\title{
Announcement
}

\section{The H.T. Odum Synthesis Essay, a new section in Estuaries}

The death of Howard $T$. Odum in 2002 represented the loss of one of the champions of ecosystem and estuarine science. II.T, Odum made longlasting contributions to both these fields and is particularly celebrated for his unique capacity to deliver a synthetic view of the functioning of ecosystems. The exponential growth of the published literature over the past decades has enhanced even further the need to articulate the many pieces of research published annually into coherent syntheses that highlight patterns and trends, identify inconsistencies and discrepancies, and confront them with the wider context of coastal and estuarine science.

We are proud to announce the initiation of a new series of papers in Estuaries, the H.T. Odum Synthesis Essays, conceived with the dual goal of celebrating Howard T. Odum and delivering much needed synthesis on important current topics in coastal and estuarine science. The HTT. Odum Syn- thesis Essay will be published annually, and will be invited by the co-Editors-in-Chief of the journal to address a subject of particular relevance where a well articulated synthesis is deemed necessary. The H.T. Odum Synthesis Essays will combine rigorous factual accounts of the state of the art with the opportunity for the author to provide their view on the current status of the subject and the challenges ahead. We believe this to be an important service to the scientific community, which does not have a dedicated outlet where such synthesis papers may be found, as well as a new, high-profile component of Estuaries, raising the visibility of both the journal and the work of the authors invited to contribute to this new important section.

$$
\begin{array}{r}
\text { Carlos M Duarte and Scott Nixon } \\
\text { Co-Editors-in-Chief } \\
\text { Stephen Threlheld } \\
\text { Managing Editor Estuaries }
\end{array}
$$

